\title{
Developing the Leader-Member Exchange Theory in Nursing: Seeing from an Introvert Eye
}

\section{Laksita Barbara}

Faculty of Health Science, Muhammadiyah University of Surabaya

Citation: Barbara, L. (2018). An opportunity to develop the Leader-Member Exchange theory: Seeing from an introvert eye. Jurnal Keperawatan Muhammadiyah, 3 (1)

Objective: This paper aims to find a gap in the current
laksitabarbara@gmail.com $\begin{aligned} & \text { Leader-Member Exchange }(L M X) \text { theory with regards of } \\ & \text { introversion }\end{aligned}$

Keywords: introvert, leader-member exchange, nursing management
Methods: A literature review is conducted to analyse the current findings of the development and application of LMX theory.

Results: The LMX theory focuses on the interaction that happens in leadership and reveals the role of relationship in affecting the organisation outcomes. The LMX theory has been developed in four stages to meet the needs of the application at various organisational levels. In the nursing profession, the application of LMX theory shows positive outcomes in affective commitment, job satisfaction, and reduced intention to leave. However, the studies of this theory in nursing has hardly provided the solution to overcome the limitations of out-group members. The studies show the discrimination that is caused by the different treatment of the leader to each member. The other issue is subjectivity. The high-quality interaction is more likely to be formed by people with sociable traits compared to those with solitaire personality. One of the personality types which might have a less likeliness to be the in-group member is introverted personality.

Conclusion: The LMX theory has given a pivotal awareness in nursing profession regarding the different relationship developed by a supervisor with each nurse. However, there is hardly prescriptive approach to escalating the exchange quality to the higher level. Thus, this paper emphasises the need to enhance justice climate and identify as well as be aware of the leader's and member's characteristics.

\section{INTRODUCTION}

The leader-member exchange (LMX) theory has been widely known and applied worldwide. This theory emphasises the importance of the interaction between a leader and each subordinate. Based on the LMX theory, members with the high- 
quality exchange are privileged with adequate support and more opportunity for career development (Graen \& Uhl-Bien, 1995; Winkler, 2010). The in-group members develop trust, respect, and obligation which provides a better information flow and engagement to more organisational activities (Portoghese et al., 2012). These interactional benefits are essential in adhering organisational change or achieving goals of professions in the workplace. In the nursing profession, this leadership approach is pivotal to overcome nurses' shortage in several countries (Brunetto, Farr-Wharton, \& Shacklock, 2010; Farr Wharton, Brunetto, \& Shacklock, 2012). However, the existence of out-group members that are not at the privileges is inevitable. Brunetto et al. (2010) argue that the out-group members are more likely to have a low-level engagement to the organisation since they experience less autonomy than the outgroup. The selection of out-group and ingroup members could be related to the ability of the personals to be open and proactively interact with the leader, despite the role of leader itself to engage the members. According to Dienesch and Liden (1986), the development of LMX starts with an initial interaction in which the leader and each member bring their personal characteristics which determine the further step in the relationship. This theory is supported by Winkler (2010) who argues that extroversion plays an important part in impressing the leader. Hence, the introvert members have characters that make them more likely to be excluded from the cycle of in-group. Thus, this paper aims to find a gap in the current findings and provide a recommendation by exploring the LMX theory with regards of introversion.

\section{THE ESSENTIALS OF LEADER- MEMBER EXCHANGE THEORY}

There are different ways of analysing leadership theories. Some theories explore leadership through the role of the leader itself. For instance, the trait and behavioural leadership see the leader as the role that determines leadership effectiveness through his/her characteristics and behaviours (Derue, Nahrgang, Wellman, \& Humphrey, 2011). Some other theories emphasise the effectiveness criteria defined through members' perspectives. One of these theories is empowerment theory which value staffs' performance as a determining factor of a successful leadership (Magni \& Maruping, 2013). The final theory category is developed based on the interaction that happens between these two domains, which is also called the relationship domain. The leader-member exchange is one of the theories from the relationship perspective (Graen \& UhlBien, 1995). The following section will provide a general description to understand LMX theory. Other theories within relationship domain are also discussed through further understanding of the LMX evolution stages will be explained in the later section.

Focusing on the interaction that happens in leadership, the leader-member exchange theory has revealed the role of relationship in affecting the organisation outcomes. According to this theory, a leader has differentiated relationship with each member which causes a different type of exchange qualities and in turn, different outcomes of each staff (Brunetto et al., 2010; Davies, Wong, \& Laschinger, 2011). This theory has challenged the average leadership style and captured the reality of differentiated dyadic relationship (Graen \& Uhl-Bien, 1995). As in nursing, the evolution of managerial structure which gives more authority to the supervisors has reduced the autonomy of nurses in doing their nursing care (Brunetto, FarrWharton, \& Shacklock, 2011). Without an understanding of how a high-quality relationship can be developed, this organisation change is likely to lead to role unclarities and decreased satisfaction of staff roles. The LMX theory has been 
developed in four stages to meet the needs of the application at various organisational levels. This paper will discuss the first until the third stage since it will focus on the movement from the descriptive stage to the prescriptive stage.

When first developed, LMX theory is only for a descriptive purpose. According to Graen and Uhl-Bien (1995), the first form of LMX theory was the Vertical Dyad Linkage (VDL) which explored the relationship of a leader with each member. In this early stage, the theory was limited to the description of the low-quality and high-quality relationship between a leader as superior, and members as subordinates (Winkler, 2010). This theory emphasises the idea that a leader is most likely to engage few followers, who have a highquality exchange with the leader, in the ingroup.

On the second stage of the development, LMX theory has moved from describing dyadic relationship into analysing how the relationship is formed and what are the consequences of this relationship. Winkler (2010) summarises the studies in this stage which had a focus on the outcomes including members' satisfaction, turnover rate, performance, and commitment. The consequences of two types of relationship were studied, revealed the advantages of in-group, and the drawbacks of out-group (Dienesch \& Liden, 1986). However, this theory could not provide a further prescription of how to make a high-quality LMX and how to overcome the disadvantages of a low-quality LMX.

It was not until the studies of leadership making theory that the equity issue was explored. This third stage offers the more comprehensive approach into how a highquality exchange could be built. This stage of LMX development proposed that leader should offer the same opportunity for all members to develop a high-quality exchange (Graen \& Uhl-Bien, 1995). The leadership making theory suggests a journey from a superior-subordinate relationship to a partnership, and equity for all members to maximise the number of ingroup members (Graen \& Uhl-Bien, 1995). There are three phases of relationship maturity that should be developed to achieve a high-quality exchange.

The first phase comprises a superficial formal interaction which represents an outgroup communication (Graen \& Uhl-Biel, 1995). Interestingly, this phase of leadership making has similar key features with the transactional leadership. In the transactional leadership theory, the exchange between two parties is based on the benefits that could be obtained which motivate the relationship to be continued or dismissed (Sullivan, 2012). The interaction in both the first phase of leadership making and the transactional leadership is procedural and motivated by self-interests which also can be classified as a low-level LMX.

The second phase of the leadership making process determines the relationship direction towards the in-group exchange. In this phase, the acquaintance phase, there are more information exchanges outside the job description and the trust is being strengthened along with the delegation of extra responsibilities (Graen \& Uhl-Bien, 1995). The characteristic of this development phase also can be seen in the transformational leadership approach which moves the focus beyond selfinterest to self-development. This theory argues that the relationship in leadership should motivate members to improve their leadership skills (Sullivan, 2012). If the acquaintance phase can be developed successfully, the superior-subordinate relationship can be moved toward a partnership (Graen \& Uhl-Bien, 1995). Otherwise, the process will have to move back to the first phase since the leader will consider this intermediate phase as a determinant step to examine whether the trust is worth developing (Winkler, 2010). A mature relationship characterises the final phase of the leadership making. Having a high level of support, trust, and 
respect, the members who have successfully entered this mature phase would be able to gather benefits of the ingroup relationship (Brunetto,2010). Despite the unlikeliness that all members could develop a partnership in the leadership making theory, this third LMX development stage has emphasised the equity for all members to be invited into in-group (Graen \& Uhl-Bien, 1995).

From the discussion above, positive aspects can be seen from the development of LMX theory. These aspects become a strength of LMX theory that makes it different from other leadership theories. Firstly, this theory has risen an awareness of the reality that the exchange quality determines the success of members to be allocated in the in-group which predominantly have more privileges. Secondly, this theory provides a description of how an exchange develops into a higher quality and the importance of communication in leadership. It describes how a high-quality LMX could give benefits to the dyadic personals, and the consequences of being the out-group members in the relationship. Lastly, this theory is supported by numbers of evidence which show solid results across workplaces and countries. These studies include the ones conducted in nursing field which will be summarised in the next section.

\section{CURRENT FINDINGS IN NURSING}

The LMX theory has been correlated with many outcomes in various organisations and professions across countries. In the nursing profession, many settings experience nurses' shortage which makes the turnover issue significant and pivotal (Trinchero, Borgonovi, \& Farr-Wharton, 2014). Hence, studies have been conducted to prove the contribution of the exchange quality to nurses' retention. The related outcomes include affective commitment, job satisfaction, and intention to leave. The additional effect that is currently studied is safety practice in the workplace which adds an interesting contribution for clinical settings.

The first outcome that is commonly studied is affective commitment. This term can be described generally as a feeling of attachment to an organisation (Brunetto et al., 2010). There are substantial numbers of evidence that suggest a positive correlation between LMX quality with the affective commitment of nursing staffs (Brunetto et al., 2011; Laschinger, Finegan, \& Wilk, 2009; Portoghese et al., 2012; Robson \& Robson, 2016; Trinchero et al., 2014). The LMX quality has an indirect and direct correlation with affective commitment. For instance, a study by Portoghese et al. (2012) proposes that a high-quality exchange is connected to increased nurses' expectation to organisational change which in-turn determines affective commitment. The direct influence of LMX to commitment can be seen in Brunetto et al. (2011), Trinchero et al. (2014), and Robson and Robson (2016) studies which confirm the positive correlation between LMX quality and affective commitment of nurses. Another study combined LMX quality with structural empowerment which has a positive correlation with psychology empowerment and commitment (Laschinger et al., 2009). These findings show that in order to enhance nurses' feeling of being a part of the organisation, the quality of supervisor-nurse communication should be taken into account.

The job satisfaction becomes the next outcome that is related to LMX. The findings of several studies show a positive association between LMX quality and job satisfaction of nurses (Han \& Jekel, 2011; Laschinger, Finegan, \& Wilk, 2011; Laschinger, Purdy, \& Almost, 2007). The idea is that recognition by the leader and benefits offered in the partnership could increase the nurses' pleasure about their work (Han \& Jekel, 2011). The direct connection can be seen in Han and Jekel (2011), while the indirect connection is 
shown in Laschinger et al. (2007). Laschinger et al. (2011) in the later study also proposes the indirect and direct correlation of LMX with job satisfaction in one study. The two results that suggest the indirect correlation between the two variables put the empowerment element as mediation. The environment created by the leader in order to empower the nurses decreases psychological exhaustion which causes a higher job satisfaction (Laschinger et al., 2011). The link between exchange quality and empowerment could also be related to a study by Davies et al. (2011) which shows a high participation in knowledge transfer in a high-quality LMX. This knowledge sharing is an essential part of the empowerment process.

The affective commitment and job satisfaction consequently influence nurses' intention to stay in the organisation. However, the connection between LMX and turnover intention is also explored in several studies (Han \& Jekel, 2011; Portoghese, Galletta, Battistelli, \& Leiter, 2015; Robson \& Robson, 2016). These studies show similar results which suggest the opposing association between LMX quality and the leave intention. That is to say, the higher quality of supervisorsubordinate relationship could be related to a lower turnover intention.

Not only does the LMX has positive outcomes for nursing workforces, the benefits for health consumers are also proposed. Thompson et al. (2011) suggest that high-quality exchanges result in an increased number of safety promotion and compliance in safe practices. This study also addresses the better information flow regarding staffs' report of missed nursing care as well as supervisors' concern and advice in safe practices. This information flow is defined by Mattson, Hellgren, and Göransson (2015) as the safety priority communication. In this study, the communication style of the leader influences the incident reporting rate, staffs' compliance, and, consequently, patient safety. The similar finding is also reported by Kim, Kang, Kim, and You (2014) who emphasise the influence of a supportive relationship in nurses' willingness to speak out since they believe the leader will provide assistance. That is to say, a high-quality interaction between the supervisor and the members lead to a mutual trust and support which are important aspects of increasing incident reports. As a consequence, the prevention rate of unsafe practice could be enhanced. These outcomes have supported the second stage of LMX theory development which is exploring the effect of the high-quality and the low-quality exchange. The LMX theory has been developed to provide the best understanding of the relationship development process to enhance the leadership outcomes. However, a question remains: Has this theory achieved a perfect form to explain how to build a high-quality exchange for all members?

\section{THE ISSUES}

Despite the compact findings that emphasise the importance of building a high-quality communication between leaders and members, the studies of LMX theory in nursing has hardly provided the solution to overcome the limitations of out-group members. Furthermore, it is explained in the LMX theory that the failure of bringing the second phase of the relationship to the third phase is inevitable in an organisation (Graen \& Uhl-Bien, 1995). These drawbacks might reduce the applicability of this theory to nursing practice. As discussed in the previous section, the LMX theory has divided the relationship quality into two groups: one has privileges of the leadership, and the other does not. The third stage of LMX theory development, namely leadership making theory, has explored how a highquality LMX is developed with an emphasise on equality of the opportunity offered by the leader. However, the inadequacy of the approach in engaging the out-group members remains (Winkler, 2010). This disadvantage is most likely to 
inflict a discrimination and inequity issue. The characteristics of the leaders and members might contribute to this issue. Thus, this paper will also discuss psychological types based on extroversion. The first drawback of this theory is the discrimination that is caused by the different treatment of the leader to each member. According to Han and Bai (2014), the different quality of relationship in LMX has a negative association with nurses' perception of interaction and distribution justice. That is to say; nurses are more likely to feel unfairness when the supervisor provides different resources and shows different treatment to each member within the team. This perceived injustice is more likely to affect out-group members when explored at the individual level. Unfortunately, the studies of justice perception of LMX in the nursing profession are very limited. However, this issue also exists in other contexts of LMX application. As Furunes, Mykletun, Einarsen, and Glasø (2015) propose that lower-quality LMX is correlated with discrimination and unfairness. The similar finding is also reported by Williams, Scandura, Pissaris, and Woods (2016) who associate low-quality exchange with lowlevel of interactional justice. These findings confirm the inadequacy of LMX theory regarding inequity in providing resources, especially for out-group members, despite the 'equal offer' concept proposed in the third stage of the theory development.

The characters of the members are alleged to contribute to the in-group and out-group membership's distribution which tends to make the traits of people within a group homogenised. In other words, the highquality interaction is more likely to be formed by people with sociable traits compared to those with solitaire personality. Thus, the potential drawback is related to the personal character of the members who have the lower opportunity in developing a high-quality LMX. In the past study by Dienesch and Liden (1986), a critique was proposed regarding the development of LMX theory. They suggested that each member of a dyadic relationship brings their characteristics in the initial interaction which might determine the next step of the relationship (Dienesch \& Liden, 1986). In other words, the members' characteristics may or may not impress the leader which influence the leader's decision to offer a further interaction.

One of the personality types which might have a less likeliness to be the in-group member is introverted personality. Without any intention of ignoring other personality classification theories, this paper will discuss introvert and extrovert classification regarding the benefits and drawbacks of each psychological type in developing a relationship in the workplace. One way in describing introverted and extroverted personalities is by their action and reflection process. According to Jung (1971), extroverted people can effortlessly project their actions outwards without any significant interference of their thought. In contrary, introverted individuals are defined by their inner self without any tendency of making an impression towards their surrounding (Jung, 1971). For instance, in an interaction with people, extroverts can lively talk with others without a long thinking process, even without prior thinking, which enables them to have more feedback from others. On the other hand, introverts need to reflect their potential interaction before making a real one which often limits their communication. The introverted workers also tend to have a higher level of protection of their privacy, which makes them less open to others in topics outside their professional area (Baer, Jenkins, \& Barber, 2016). Thus, the leadership making process could be more challenging for introverts since they might have a tendency responding the offer more carefully and thoughtfully. This difficulty is also stated by Myers and McCaulley (1985) who developed a measurement to 
place individuals to an appropriate career. According to their career classification for various psychological types, while extroverts are enjoying activities among people with a lot of interactions, introverted people are more contented working alone without much communication with others. In other words, without much interaction, introverted followers are more likely to be excluded from wider information access or decision-making process.

The other drawback of the LMX model is the subjectivity in deciding the in-group and the out-group members. The findings that have been discussed reveals the lack of studies evaluating the performance of in-group and out-group members. In Davidson, Gillies, and Pelletier (2015), it is suggested that introverted clerks did very well in the university years, but received a low mark on the interaction evaluation in the clerkship. This also mean that introverts' lack of communication interest does not necessarily correlate with their practical skill. However, the LMX theory lays stress on a personal closeness regardless the members' performance (Graen \& Uhl-Bien, 1995). Hence, the introverts have a less opportunity to be included in the in-group members despite the skills they may have. Current studies report a positive association between LMX quality and members' performance (Loi, Ngo, Zhang, \& Lau, 2011; Vidyarthi, Liden, Anand, Erdogan, \& Ghosh, 2010; $\mathrm{Xu}$, Simon, Wing, \& Xinsheng, 2010). However, these findings used subjective reports from the supervisors. In the nursing profession, the exclusion of skilled staffs from the privileged group would probably happen if the performance evaluation relies solely on supervisors' opinion. Therefore, there is a need for further exploration in performance area regarding the objective measurement since skilled nurses could have more intention to leave if they are excluded from the privileged group.

\section{RECOMMENDATIONS}

This paper proposes recommendations regarding the need for further development of LMX theory. The first recommendation is improving justice climate to reduce the discrimination in the theory application. The second recommendation is maximising the engagement of low-quality exchange members. This paper also recommends to consider the psychological types which require an integration of other leadership theories.

There are studies which include moderation role of several variables to identify the potential of reducing perceived unfairness. Based on a study by Erdogan and Bauer (2010), the differentiated exchange contributes to members' negative work attitudes and behaviours. However, this result was only shown within a low justice climate. Justice climate is defined as collective perceptions about justice received by an entire team (Cobb \& Lau, 2015). Pichler et al. (2016) emphasise the importance of the group perceptions of how they are treated, namely procedural justice climate, on the individual-level perception. Moreover, the higher the task interdependence in a team, the stronger the influence of perceived justice in the team (Han \& Bai, 2014). That is to say, the issues caused by the differentiated exchange are more likely to be eliminated if the leader shows an objective feedback to all members. Thus, the members, representing the whole team, would have a positive justice perception which could embrace and motivate the out-group to engage in the exchange.

In embracing the out-group members to improve the LMX quality, this paper suggests the integration of leader-member characteristics' congruency. As discussed in the previous session, based on LMX theory, a leader develops a relationship with each follower differently. This aspect of LMX is supported by the finding of Farr Wharton et al. (2012), that suggests a manager using a different approach to the staffs based on their character or 
attributes since the average management model showed different response across generations. However, so far, the development of LMX theory merely corroborate the exchange quality development process with less prescriptive approach regarding members' traits. Different combinations of characteristics between leaders and followers are likely to result in different LMX qualities. Zhang, Wang, and Shi (2012) provide an interesting finding of the congruency of the leader's and the member's personality. They suggest that the combination of a less-proactive leader with a highly proactive follower produce a better LMX quality compared to the different combination. Interestingly, a low-level proactive personality member could build a better LMX quality with a less proactive leader (Zhang et al., 2012). Thus, sharing an understanding about leader's and member's characteristics and expectations of the dyadic relationship is essential to develop a better exchange quality (Nasrullah, D., \& Wibowo, N. A., 2016)

Supporting the importance of considering each personality combination, the last recommendation raises the awareness of introversion and extraversion. In recruiting or placing staffs in the workplace, personality assessment is widely applied. Thus, in developing the high-quality LMX, extraversion of the members and leaders is also need to be taken to account. The introversion of the members is not the only determining factor in leadership. Different from the extroverts who are more likely to get experience away from the table, introvert leaders might prefer less interdependence teamwork since they can work solitary with less interaction (Myers \& McCaulley, 1985). Each personality has its strengths and weaknesses. Identifying personality of oneself could assist the leader and the member in making an adjustment in the interaction, decreasing their limitation, and improving their potential.

\section{CONCLUSION}

The relationship approach in LMX theory has given a pivotal awareness in nursing profession regarding the different relationship developed by a supervisor with each nurse. The studies in LMX theory emphasise the importance of developing a high-quality exchange to obtain benefits for the nurses, the organisations, and the patients. There are substantial findings across countries that suggest the firm evidence of the benefits of high-quality LMX. It indeed motivates the leaders in nursing to develop this kind of relationship. However, there is a hardly prescriptive approach to escalating the exchange quality to the higher level. The differentiated exchange quality results in perceived inequality within the members. There is also the lack of recognition of each member's characteristic which could influence the interaction within a dyadic relationship. Thus, this paper emphasises the need for leaders' objectivity to enhance justice climate in the team. It is also recommended to identify and be aware of the leader's and member's characteristics, including their extraversion, to help them adjust their interaction in the dyadic relationship.

\section{REFERENCE LIST}

Baer, S. M., Jenkins, J. S., \& Barber, L. K. (2016). Home is private... Do not enter! Introversion and sensitivity to work-home conflict. Stress and Health, 32(4), 441-445. doi:10.1002/smi.2628

Brunetto, Y., Farr-Wharton, R., \& Shacklock, K. (2010). The impact of supervisor-subordinate relationships on morale: implications for public and private sector nurses' commitment. Human Resource Management Journal, 20(2), 206-225. doi:10.1111/j.17488583.2009.00117.x 
Brunetto, Y., Farr-Wharton, R., \& Shacklock, K. (2011). Supervisor-subordinate communication relationships, role ambiguity, autonomy and affective commitment for nurse. Contemporary Nurse, 39, 227+. doi:10.5172/conu.2011.39.2.227

Cobb, A. T., \& Lau, R. S. (2015). Trouble at the next level: Effects of differential leader-member exchange on group-level processes and justice climate. Human Relations, 68(9), 1437-1459. doi:10.1177/0018726714557873

Davidson, B., Gillies, R. A., \& Pelletier, A. L. (2015). Introversion and medical student education: Challenges for both students and educators. Teaching and Learning in Medicine, 27(1), 99-104. doi:10.1080/10401334.2014.97918 3

Davies, A., Wong, C. A., \& Laschinger, H. (2011). Nurses' participation in personal knowledge transfer: The role of leader-member exchange (LMX) and structural empowerment. Journal of Nursing Management, 19(5), 632-643. doi:10.1111/j.13652834.2011.01269.x

Derue, D. S., Nahrgang, J. D., Wellman, N. E. D., \& Humphrey, S. E. (2011). Trait and behavioral theories of leadership: An integration and meta-analytic test of their relative validity. Personnel Psychology, 64(1), 7-52. doi:10.1111/j.1744-

6570.2010.01201.x

Dienesch, R. M., \& Liden, R. C. (1986). Leader-member exchange model of leadership: A critique and further development. Academy of Management Review, 11(3), 618634.

doi:10.5465/AMR.1986.4306242

Erdogan, B., \& Bauer, T. N. (2010). Differentiated leader-member exchanges: The buffering role of justice climate. Journal of Applied Psychology, 95(6), 1104-1120. doi:10.1037/a0020578

Farr Wharton, R., Brunetto, Y., \& Shacklock, K. (2012). The impact of intuition and supervisor-nurse relationships on empowerment and affective commitment by generation. Journal of Advanced Nursing, 68(6), 1391-1401. doi:10.1111/j.13652648.2011.05852.x

Furunes, T., Mykletun, R. J., Einarsen, S., \& Glasø, L. (2015). Do low-quality leader-member relationships matter for subordinates? Evidence from three samples on the validity of the Norwegian LMX scale. Nordic Journal of Working Life Studies, $5(2)$, 71-87. doi:10.19154/njwls.v5i2.4794

Graen, G. B., \& Uhl-Bien, M. (1995). Relationship-based approach to leadership: Development of leadermember exchange (LMX) theory of leadership over 25 years: Applying a multi-level multidomain perspective. The Leadership Quarterly, 6(2), 219247. doi:10.1016/10489843(95)90036-5

Han, G., \& Bai, Y. (2014). In need of each other: The moderator of task interdependence between LMX variability and justice. Journal of Nursing Management, 22(6), 743750. doi:10.1111/jonm. 12009

Han, G., \& Jekel, M. (2011). The mediating role of job satisfaction between leader member exchange and turnover intentions. Journal of Nursing Management, 19(1), 4149. 2834.2010.01184.X doi: $10.1111 /$ j.1365-

Jung, C. G. (1971). Psychological types (H. G. Baynes, Trans.). New York: Princeton University Press.

Kim, M. Y., Kang, S., Kim, Y. M., \& You, M. (2014). Nurses' willingness to 
report near misses: A multilevel analysis of contributing factors. Social Behavior \& Personality: an international journal, 42(7), 11331146. doi:10.2224/sbp.2014.42.7.1133

Laschinger, H. K. S., Finegan, J., \& Wilk, P. (2009). Context matters: The impact of unit leadership and empowerment on nurses' organizational commitment. Journal of Nursing Administration, $39(5)$, 228-235. doi:10.1097/nna.0b013e3181a23d2 b

Laschinger, H. K. S., Finegan, J., \& Wilk, P. (2011). Situational and dispositional influences on nurses' workplace well-being: The role of empowering unit leadership. Nursing Research March/April, 60(2), 124-131. doi:10.1097/nnr.0b013e318209782 e

Laschinger, H. K. S., Purdy, N., \& Almost, J. (2007). The impact of leadermember exchange quality, empowerment, and core selfevaluation on nurse manager's job satisfaction. Journal of Nursing Administration, 37(5), 221-229. doi:10.1097/01.nna.0000269746.63 007.08

Loi, R., Ngo, H.-Y., Zhang, L., \& Lau, V. P. (2011). The interaction between leader-member exchange and perceived job security in predicting employee altruism and work performance. Journal of Occupational \& Organizational Psychology, 84(4), 669-685. doi:10.1348/096317910X510468

Magni, M., \& Maruping, L. M. (2013). Sink or swim: Empowering leadership and overload in teams' ability to deal with the unexpected. Human Resource Management, 52(5), 715-739. doi:10.1002/hrm.21561
Mattson, M., Hellgren, J., \& Göransson, S. (2015). Leader communication approaches and patient safety: An integrated model. Journal of Safety Research, 53, 53-62. doi:10.1016/j.jsr.2015.03.008

Myers, I. B., \& McCaulley, M. H. (1985). Manual: A guide to the development and use of the MyersBriggs Type Indicator (2nd ed.). Palo Alto, California: Consulting Psychologists Press.

Nasrullah, D., \& Wibowo, N. A. (2016). Efektifitas Terapi Muscong (Musik Keroncong) Untuk Menurunkan Intensitas Nyeri Pada Pasien Arthitis Rhemathoid (Studi Kasus Panti Werdha Surabaya Timur). Jurnal Keperawatan Muhammadiyah, 1(2), 115-121.

Pichler, S., Varma, A., Michel, J. S., Levy, P. E., Budhwar, P. S., \& Sharma, A. (2016). Leader-member exchange, group- and individuallevel procedural justice and reactions to performance appraisals. Human Resource Management, 55(5), 871-883. doi:10.1002/hrm.21724

Portoghese, I., Galletta, M., Battistelli, A., \& Leiter, M. P. (2015). A multilevel investigation on nursing turnover intention: The cross level role of leader-member exchange. Journal of Nursing Management, 23(6), 754-764. doi:10.1111/jonm.12205

Portoghese, I., Galletta, M., Battistelli, A., Saiani, L., Penna, M. P., \& Allegrini, E. (2012). Change related expectations and commitment to change of nurses: The role of leadership and communication. Journal of Nursing Management, 20(5), 582591. doi:10.1111/j.13652834.2011.01322.x

Robson, A., \& Robson, F. (2016). Investigation of nurses' intention to leave: A study of a sample of UK 
nurses. Journal of Health Organization and Management, 30(1), 154-173. doi:10.1108/jhom05-2013-0100

Sullivan, E. J. (2012). Effective leadership and management in nursing (8th ed.). Boston: Pearson.

Thompson, D. N., Hoffman, L. A., Sereika, S. M., Lorenz, H., Wolf, G. A., Burns, H. K., . . . Ramanujam, R. (2011). A relational leadership perspective on unit-level safety climate. Journal of Nursing Administration, 41(11), 479-487.

doi:10.1097/nna.0b013e3182346e3 1

Trinchero, E., Borgonovi, E., \& FarrWharton, B. (2014). Leadermember exchange, affective commitment, engagement, wellbeing, and intention to leave: Public versus private sector Italian nurses. Public Money \& Management, 34(6), 381-388. doi:10.1080/09540962.2014.96236 1

Vidyarthi, P. R., Liden, R. C., Anand, S., Erdogan, B., \& Ghosh, S. (2010). Where do I stand? Examining the effects of Leader-Member Exchange social comparison on employee work behaviors. Journal of Applied Psychology, 95(5), 849861. doi:10.1037/a0020033

Williams, E. A., Scandura, T. A., Pissaris, S., \& Woods, J. M. (2016). Justice perceptions, leader-member exchange, and upward influence tactics. Leadership \& Organization Development Journal, 37(7), 10001015. doi:10.1108/LODJ-02-20130021

Winkler, I. (2010). Contemporary leadership theories: Enhancing the understanding of the complexity, subjectivity and dynamic of leadership doi:10.1007/978-37908-2158-1
Xu, H., Simon, C. H. C., Wing, L., \& Xinsheng, N. (2010). The joint effect of leader-member exchange and emotional intelligence on burnout and work performance in call centers in China. International Journal of Human Resource Management, 21(7), 1124-1144. doi:10.1080/09585191003783553

Zhang, Z., Wang, M. O., \& Shi, J. (2012). Leader-follower congruence in proactive personality and work outcomes: The mediating role of leader-member exchange. Academy of Management Journal, 55(1), 111-130. doi:10.5465/amj.2009.0865 